\title{
Non-surgical management of a pediatric "intoed" gait pattern - a systematic review of the current best evidence
}

\author{
Hayley Uden' \\ Saravana Kumar ${ }^{2}$ \\ 'Podiatry Department, University \\ of South Australia, Adelaide, South \\ Australia, Australia; ${ }^{2}$ Post Doctoral \\ Senior Research Fellow, International \\ Centre for Allied Health Evidence, \\ University of South Australia, \\ Adelaide, South Australia, Australia
}

Correspondence: Hayley Uden

Campus Central - City East, University

of South Australia, GPO Box 247I,

Adelaide SA 500I, Australia

Tel +6I 883022589

Fax +61883022766

Email hayley.uden@unisa.edu.au
This article was published in the following Dove Press journal:

Journal of Multidisciplinary Healthcare

24 January 2012

Number of times this article has been viewed

Background: An intoed gait pattern is one of the most common referrals for children to an orthopedic consultation. Parental concern as to the aesthetics of the child's gait pattern and/or its symptomatic nature will primarily drive these referrals during a child's early developmental years. Whilst some of these referrals prove to be the result of a normal growth variant, some children will present with a symptomatic intoed gait pattern. Various treatments, both conservative and surgical, have been proposed including: braces, wedges, stretches and exercises, shoe modifications, and surgical procedures. However, which treatments are effective and justified in the management of this condition is not clear within the literature. The aim of this systematic review was to therefore identify and critique the best available evidence for the non-surgical management of an intoed gait pattern in a pediatric population.

Method: A systematic review was conducted of which only experimental studies investigating a management option for an intoeing gait pattern were included. Studies needed to be written in English, pertaining to a human pediatric population, and published within a peer reviewed journal. Electronic databases were searched: Ovid (Medline), EMBASE, AMED, PubMed, SportDiscus, CINAHL, and Cochrane Library. The National Health and Medical Research Council's designation of levels of hierarchy and the Critical Appraisal Skills Programme cohort studies critical appraisal tool were used.

Results: Five level IV studies were found. The studies were of varied quality and with mixed results. Gait plates, physiologic/standardized shoes, and orthotic devices (with gate plate extension) were shown to produce a statistically significant improvement to an intoed gait pattern. Shoe wedges, torqheels, and a leather counter splint were not able to reduce an intoed gait pattern.

Conclusion: There is limited evidence to inform the non-surgical management of a pediatric intoed gait pattern. The body of evidence that does exist is small $(n=5)$ and of varied quality, which means recommendations arising from this evidence base should be interpreted with caution. There is generally weak evidence that suggests that gait plates and orthotic devices with a gait plate extension may assist in the management of a pediatric intoed gait pattern.

Keywords: intoeing, toe-in, toeing in, in-toeing

\section{Background}

Intoeing or "pigeon toed" is a gait pattern in which the feet, and in fact the entire leg, will point towards each other instead of functioning in a parallel alignment during ambulation. This intoed gait pattern is one of the most common referrals made to a pediatric orthopedic specialist. ${ }^{1-6}$ Parental concern as to the aesthetics of the child's gait pattern will primarily drive these referrals..$^{3-5,7-11}$ Whilst some of these referrals will prove to be the result of a normal growth variant, ${ }^{2,9,14-19}$ some children will present with a symptomatic intoed gait pattern. Symptoms commonly reported include 
frequently tripping, clumsiness during physical activities, and fatigue like pains. . $7,13,18,19$ Parents may also be concerned with the possibility of any long term effects on their child's development. The long term ramifications of this gait pattern cited within the literature include patella-femoral pathology, abnormal subtalar joint pronation, hip joint arthrosis, and patella instability. ${ }^{20}$

There are a collection of recognized pathologies, structural and/or postural positions that can lead to an intoed gait pattern. These include metatarsus adductus, excessive femoral antetorsion, medial tibial torsion, medial genicular bias, cerebral palsy, and weak and/or dominated lateral hip rotators. ${ }^{4,5,8,9,14-16,21-26}$ An intoed gait pattern therefore is truly the overall result of one of these underlying pathologies. It would stand to reason then, that an effective and targeted management plan requires the accurate diagnosis of one of these underlying pathologies.

Primarily the diagnosis of an intoed gait pattern is simply made by a clinical gait analysis. The degree of intoeing or outtoeing can be determined using the Foot Progression Angle (FPA). 2,3,7,17,24,27-31 This angle is formed by the line of progression (direction of gait) and the bisection of the person's foot print. The foot bisection line used to calculate the FPA varies greatly within the literature. ${ }^{27}$ Albeit only one pilot study, Milliron and colleagues, concluded that the center of the second toe be used as the anterior mark for the foot bisection line in FPA measurements. This method produced the lowest standard deviation and lowest variation values $(4.47 \pm 5.95)$, when compared to three other bisection methods (intermetatarsal space 1st and 2nd, space 2nd and $3 \mathrm{rd}$, and center of the $3 \mathrm{rd}$ toe print). ${ }^{27}$

The normal FPA ranges for children through to adults are reported to be within $-3^{\circ}$ and $+20^{\circ}$ (a minus sign denoting an intoed gait pattern). ${ }^{30}$ A measurement in excess of 2 SDs (standard deviations) is said to be indicative of an abnormal FPA. ${ }^{3,7,29}$ Whilst a measurement outside these values should suggest an abnormal gait pattern, there is no indication as to what degree of intoeing would constitute a pathological outcome. Thus the question of whether "to treat, or not to treat?" is still a pertinent question for a clinician when treating a pediatric patient, especially in the absence of pain. ${ }^{7,14,32}$ Simply put, if a child presents to a clinician with an intoed gait pattern with no pain, should this condition be treated?

There are a plethora of treatments, both conservative and surgical, that have been proposed within the literature to be effective for the management of an intoed gait pattern; including braces, wedges, stretches and exercises, shoe modifications, and various surgical osteotomies. ${ }^{2-15,22-26,31}$ However, when a clinician is presented with a concerned parent and an intoed child, there are currently no best evidence based management strategies available. In the absence of established best evidence based practice, the provision of both safe and quality health care cannot be assured. The aim of this systematic review was to therefore identify and critique the best available evidence for the non-surgical management of an intoed gait pattern in a pediatric population.

\section{Methods}

\section{Search strategy}

A systematic search using the following search terms was conducted by one of the authors (HU): Intoe*, toe-in, toeing in, in-toe*, pigeon toe*, $\mathrm{p}^{*}$ ediatric* within the following electronic databases from inception to August 2011: Ovid ((Medline) 1950 to August 2011), EMBASE (1996 to August 2011), AMED (1985 to August 2011), PubMed, SportDiscus, CINAHL, and Cochrane Library. "Pearling" of the retained reference lists was also conducted in an effort to identify any articles that may have been missed from the above search strategy.

\section{Inclusion/exclusion criteria}

Studies needed to be of experimental design, written in English, pertaining to a human pediatric population ( $<18$ years of age), and published within a peer review journal. The population needed to be a pediatric population with no neurological or systemic pathologies (such as cerebral palsy) with an intoed gait pattern. Studies needed to implicitly state that the objective of their study was to manage an intoed gait pattern with a non-surgical method. All potential search "hits" were screened by both authors (HU and SK) for relevance to this review.

\section{Data extraction}

Data extraction was conducted by both authors (HU and SK) first independently with the results then compiled cohesively. Data collected was inclusive of the key characteristics of the studies (including: number of participants, population characteristics, treatment modality), outcome measures used, and the results as reported by the studies.

\section{Methodological quality assessment}

The assignment of the level of evidence of the retained studies was completed by both the authors (HU and SK) independently, with the results then compiled. The National 
Health and Medical Research Council's designation of levels of evidence was used to assign the articles..$^{33}$ The Critical Appraisal Skills Programme critical appraisal tool, which was publicly available and widely used in systematic reviews, was used to objectively appraise the retained articles. ${ }^{34}$ The tool contains twelve questions based around the following three overarching themes: are the results of the study valid?, what are the results?, and will the results help me locally? A response of "yes," "no," or "can't tell" is assigned to each question. The first two questions are considered screening questions, whilst the remainders are a mix of closed and open questions. This tool can be freely accessed from the Public Health Resource Unit website. ${ }^{34}$

\section{Body of evidence}

To aid in the interpretation and comprehension of the findings of this review, the National Health and Medical Research Council's body of evidence framework was used. ${ }^{35}$ This framework enables evidence based recommendations to be made despite there being a varied body of literature from which the recommendations are being drawn. The framework is composed of five components: evidence base, consistency, clinical impact, generalizability, and applicability of the research. Both authors have experience in successfully using this framework to interpret varied bodies of research.

\section{Results}

\section{Search results}

A moderate total of 178 search "hits" were found from running the above search strategy. Of these initial search "hits" only five studies met the inclusion criteria and were retained for this review. No new studies were identified through the "pearling" process. Figure 1 provides an overview of the literature selection process.

\section{Characteristics of studies}

Table 1 contains a summary of the study characteristics. These five studies represent the current best available level of evidence in the non-surgical management of an intoed gait pattern in a pediatric population (level IV - case series). Of note, three studies reported specific subject inclusion and exclusion criteria for their cohorts, whilst only two studies further described the presence of the underlying etiologies of their intoeing cohort. ${ }^{3,7,14,20} \mathrm{~A}$ total of four different interventions were reported: a flexible leather counter splint, shoe modifications, gait plates, and an orthotic device with a gait plate extension. The descriptions of each treatment method as described within each of the studies are as follows:

Flexible leather counter splint - a leather strap which is attached to the lateral aspect of a pair of shoes and set to varying degrees of external rotation. The splint was attached to any normal, orthopedic, straight-last, prewalker, surgical, or out flare shoe. ${ }^{26}$ The installation of this device was conducted within the clinician's office. The use of this device was broadly advocated by Lanier to be for postural driven torsional abnormalities.

Shoe modifications - encompass a series of sole wedges, sole and heel wedges, heel wedges, torqheels (parallel), and torqheels (circular). These modifications were made to a pair of "conventional low cut, properly fitted shoes." 14

Gait plate - constructed from a piece of stiff thermoplastic material which covered the entire length of the plantar surface of the foot, finishing distally at the metatarsophalangeal heads. At the distal lateral edge, the gait plate was extended to the 5 th toe and then cut at a $45^{\circ}$ angle to sit proximal to the 1st metatarsophalangeal head at the distal medial edge. The gait plate was proposed to "block" propulsion from the lateral side of the device (intoed gait pattern) and promote propulsion from the 1st metatarsophalangeal joint. Gait plates are reported to work best in a soft soled shoe with excessive flexion. ${ }^{?}$

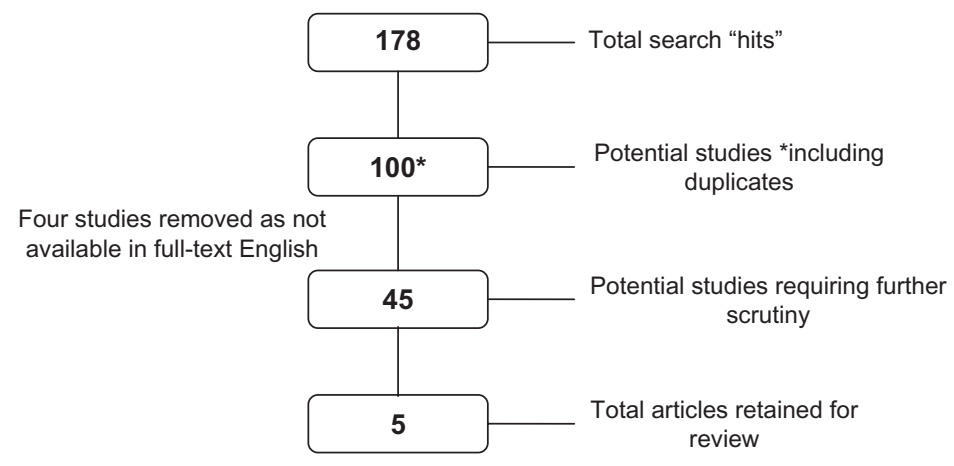

Figure I Literature selection flow chart. 
Table I Summary of study characteristics

\begin{tabular}{|c|c|c|c|c|c|}
\hline Authors & Type of study & Intervention & Population recruited & $\begin{array}{l}\text { Age range } \\
\text { (mean } \pm \text { SD) }\end{array}$ & $\begin{array}{l}\text { n females: } \\
\text { n males }\end{array}$ \\
\hline Lanier $^{26}$ & IV & $\begin{array}{l}\text { Flexible leather } \\
\text { counter splint }\end{array}$ & $\begin{array}{l}\text { Inclusion: Pediatric population with a clinical } \\
\text { diagnosis of an intoed gait (no details as to } \\
\text { the clinical measurements used) }\end{array}$ & $\begin{array}{l}<\text { I year- } \\
6 \text { years }\end{array}$ & NR \\
\hline $\begin{array}{l}\text { Knittle and } \\
\text { Staheli }{ }^{14}\end{array}$ & IV & $\begin{array}{l}\text { Shoe } \\
\text { modifications }\end{array}$ & $\begin{array}{l}\text { Inclusion: Pediatric population with a bilateral } \\
\text { intoed gait } \\
n=3 \text { Dx Femoral anteversion } \\
n=2 \text { Dx tibial torsion } \\
n=4 \text { Dx femoral anteversion + tibial torsion } \\
n=I \text { Dx tibial torsion + metatarsus adductus }\end{array}$ & $(6.2 \pm 2.5)$ & $6: 4$ \\
\hline Redmond $^{7}$ & IV & Gait plates & $\begin{array}{l}\text { Inclusion: Pediatric population with an intoed gait. } \\
\text { Minimum of } 3^{\circ} \text { of intoeing (in excess of } 2 \text { SDs from } \\
\text { Staheli's normal values) and a history of tripping } \\
n=21 \text { limbs (58\%) Dx HJ pathology } \\
n=15 \text { limbs (42\%) Dx KJ pathology }\end{array}$ & $\begin{array}{l}18 \text { months- } \\
47 \text { months }\end{array}$ & $12: 6$ \\
\hline Redmond ${ }^{3}$ & IV & Gait plates & $\begin{array}{l}\text { Inclusion: Pediatric population with an intoed gait. } \\
\text { Minimum of } 3^{\circ} \text { of intoeing (in excess of } 2 \text { SDs from } \\
\text { Staheli's normal values) and a history of tripping } \\
n=21 \text { limbs (58\%) Dx HJ pathology } \\
n=15 \text { limbs (42\%) Dx KJ pathology }\end{array}$ & $\begin{array}{l}18 \text { months- } \\
47 \text { months }\end{array}$ & $12: 6$ \\
\hline Munuera et $\mathrm{al}^{20}$ & IV & $\begin{array}{l}\text { Orthotic device } \\
\text { (with gait plate } \\
\text { extension) }\end{array}$ & $\begin{array}{l}\text { Inclusion: Pediatric population with an intoed gait. } \\
\text { Exclusion: Motor alterations or serious deformities } \\
\text { of the lower limb that would affect gait; history } \\
\text { of surgical management of the lower limb; presented } \\
\text { requiring surgical management }\end{array}$ & $(6.88 \pm 3.25)$ & $26: 22$ \\
\hline
\end{tabular}

Orthotic device (with gait plate extension) - a pair of $3 \mathrm{~mm}$ polypropylene (semi-rigid) custom foot orthoses produced from a positive cast of the "neutral" subtalar joint position. "An out-toeing wedge consisting of a distal extension of the material of the orthotic device that selectively overshoots the metatarsophalangeal articular line of the external rays and ends in a point in the subdigital space of the fifth toe."20

Due to the nature of the research design, only a small number of subjects were recruited into three of the five studies: 10, 20, and 20 respectively. Of note, Redmond's research reported on data collected from the same cohort from the same application of the intervention. ${ }^{3,7}$ No formal conclusion can be made as to any gender bias within an intoed population from the results of these studies; however, a preliminary trend of more females than males can be seen. The age distribution ranged from $<1$ year of age to 6.8 years of age.

The FPA outcome measure was used in all of the studies with the exception of the Lanier study which gave no detail as to the outcome measure utilized. ${ }^{26}$ Only two of the utilized outcome measures have psychometric properties published for their use; the questionnaires used by Redmond and the barefoot FPA method utilized within the Munuera et al report. ${ }^{3,20}$

\section{Methodological quality assessment}

Table 2 provides a summation of the closed question responses from the Critical Appraisal Skills Programme cohort studies critical appraisal tool. Although this critical appraisal tool does not assign a score, it is evident that the Lanier and Knittle and Staheli studies performed poorly in comparison to the other three studies. ${ }^{3,20}$ None of the studies had long term follow-up, with most of the studies reporting the immediate effect of the devices being trialled.

\section{Results of individual studies}

The results as reported by the various authors are displayed in Table 3. All of the results were reported quantitatively 


\begin{tabular}{lllll}
\hline $\mathbf{n}$ subjects & $\begin{array}{l}\mathbf{n} \\
\text { final }\end{array}$ & $\begin{array}{l}\text { Outcome measures } \\
\text { utilized }\end{array}$ & FPA method & $\begin{array}{l}\text { Validity and reliability of the } \\
\text { outcome measures }\end{array}$ \\
\hline 142 & 123 & NR & NR & NR
\end{tabular}

$\begin{array}{lll}10 & 10 & \text { I. Visual FPA (video) }\end{array}$

$\begin{array}{lll}20 & 18 & \text { I. FPA measurement shod } \\ (40 \text { limbs }) & (36 \text { limbs }) & \end{array}$

20

18

I. FPA measurement shod

2. Two Questionnaires
AOG measured from a line of progression with shoes on.

No detail reported as to the method used for the bisection of the shoe print

AOG measured from a line of progression with shoes on.

Bisection of the shoe print measured from the midpoint of the heel to the midpoint of the forefoot at the level of the metatarsal heads.

AOG measured from a line of progression with shoes on.

Bisection of the shoe print measured from the midpoint of the heel to the midpoint of the forefoot at the level of the metatarsal heads.

\author{
I. No validity or reliability results \\ detailed within the report or \\ within the literature for this \\ method of FPA
}

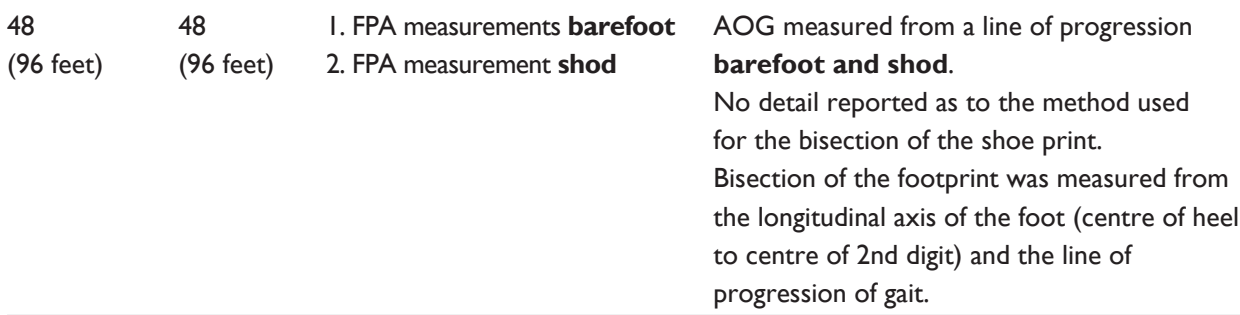

AOG measured from a line of progression barefoot and shod.

No detail reported as to the method used for the bisection of the shoe print.

Bisection of the footprint was measured from the longitudinal axis of the foot (centre of heel to centre of 2 nd digit) and the line of progression of gait.

48 (96 feet)

48

(96 feet)

I. FPA measurements barefoot

2. FPA measurement shod

\section{No validity or reliability results detailed within the report or within the literature for shod FPA}

I. No validity or reliability results reported within the report or within the literature for shod FPA

2. Validity and reliability reported as good within the report. Piloting and testing conducted several times by the author

I. Reliability results published by Milliron and colleagues (1992)

2. No validity or reliability results reported within the report or within the literature for shod FPA

Abbreviations: IV; level 4 case series with either post-test or pre-test/post-test outcomes ${ }^{33}$; NR, not reported; Dx, diagnosis; HJ, hip joint; KJ, knee joint; FPA, foot progression angle; AOG, angle of gait; SD, standard deviation.

with the exception of Lanier who reported descriptively. The Lanier study provided very little to no detail as to the treatment method, the assessment procedure, or the outcome measure used. The results were reported as three different categories: "showed improvement," "either discontinued treatment or were not improved," and "were lost to follow-up." The results reported in the category "either discontinued treatment or were not improved" is flawed because each sub-category is distinctly different and not synonymous. The two outcomes represent vastly different results and should not be reported as a singular category.

The use of a gait plate produced a statistically significant improvement to an intoed gait pattern. ${ }^{7}$ These findings were further supported with a significant improvement noted with the use of both a physiologic shoe and an orthotic device with a gait plate extension. ${ }^{20}$ However, the use of shoe wedges and circular torqheels was not shown to have a clinically significant effect on the angle of gait of children. ${ }^{14}$ One study differed from the other four by administering a questionnaire both pre and post intervention. ${ }^{3}$ Redmond used this questionnaire to assess both parental satisfaction and rates of tripping amongst the participants. A reduction in the rate of tripping and positive parental satisfaction further supports the use of gait plate devices.

\section{Body of evidence matrix}

The results of the National Health and Medical Research Council's body of evidence matrix are presented in Table 4. When assessing the current body of evidence for the nonsurgical management of an intoed gait pattern, derived from the four components of evidence, it is recommended that these intervention strategies be applied with caution. The current evidence is low level (case studies) and limited (only five studies), of questionable methodological quality, and has issues with generalizability and consistency. The results from these research initiatives however provide emerging evidence which can be used to inform future research directions. 
Table 2 Critical Appraisal Skills Programme cohort critical appraisal tool

\begin{tabular}{|c|c|c|c|c|c|}
\hline Question & Lanier ${ }^{26}$ & Knittle and Staheli ${ }^{14}$ & Redmond $^{7}$ & Redmond $^{3}$ & Munuera $^{20}$ \\
\hline $\begin{array}{l}\text { I - Did the study address a clearly } \\
\text { focused question? }\end{array}$ & Yes & Yes & Yes & Yes & Yes \\
\hline $\begin{array}{l}2 \text { - Did the authors use an appropriate } \\
\text { method to answer their question? }\end{array}$ & Yes & Yes & Yes & Yes & Yes \\
\hline $\begin{array}{l}3 \text { - Was the cohort recruited in an } \\
\text { acceptable way? }\end{array}$ & Yes & Can't tell & Yes & Yes & Yes \\
\hline $\begin{array}{c}4 \text { - Was the exposure accurately } \\
\text { measured to minimize bias? }\end{array}$ & No & No & No & Yes & No \\
\hline $\begin{array}{c}5 \text { - Was the outcome accurately } \\
\text { measured to minimize bias? }\end{array}$ & No & No & No & Yes & No \\
\hline $\begin{array}{l}\text { 6a - Have the authors identified } \\
\text { all important confounding } \\
\text { factors? }\end{array}$ & No & Can't tell & Can't tell & No & No \\
\hline $\begin{array}{l}6 \mathrm{~b} \text { - Have they taken into account the } \\
\text { confounding factors in the design } \\
\text { and/or analysis? }\end{array}$ & No & Can't tell & Can't tell & No & No \\
\hline $\begin{array}{l}\text { 7a - Was the follow-up of subjects } \\
\text { complete enough? }\end{array}$ & Can't tell & Yes & Yes & Yes & Yes \\
\hline $\begin{array}{l}\text { 7b - Was the follow-up of subjects } \\
\text { long enough? }\end{array}$ & No & No & No & No & No \\
\hline 10 - Do you believe the results? & No & Yes & Yes & Yes & Yes \\
\hline $\begin{array}{l}\text { II - Can the results be applied } \\
\text { to the local population? }\end{array}$ & No & Yes & Yes & Yes & Yes \\
\hline $\begin{array}{l}12 \text { - Do the results of this study fit } \\
\text { with other available evidence? }\end{array}$ & Can't tell & Yes & Yes & Yes & Yes \\
\hline
\end{tabular}

Note: Questions 8 and 9 were both open questions related to the results of the studies. The results for these questions are reported within Table 3.

Table 3 Results of the interventions

\begin{tabular}{|c|c|c|}
\hline Author(s) & Points of measurement & Results \\
\hline \multirow[t]{4}{*}{ Lanier $^{26}$} & NR & $73 \%$ showed improvement. \\
\hline & "Follow-up observations were made until correction & $14 \%$ either discontinued treatment or were \\
\hline & was satisfactory or patient discontinued use" pg 19 & not improved. \\
\hline & & $13 \%$ were lost to follow-up. \\
\hline \multirow[t]{4}{*}{ Knittle and Staheli ${ }^{14}$} & FPA taken in 10 different conditions: & Shoe wedges have no immediate clinically significant effect \\
\hline & 7 wedge combinations & on AOG of children. \\
\hline & 2 torqheels & Circular torqheels improved intoeing by $6.6^{\circ}$ but not a \\
\hline & I control & statistically significant improvement. \\
\hline \multirow[t]{7}{*}{ Redmond $^{7}$} & I. FPA without gait plate in shoe & Statistically significant improvement of $6^{\circ}$ of FPA \\
\hline & 2. FPA with gait plate in shoe & with gait plates in situ. \\
\hline & & Significant correlation between the severity \\
\hline & & of intoeing at initial presentation and the \\
\hline & & improvement produced with a gait plate. \\
\hline & & No correlation between site of pathology and \\
\hline & & pre and post intervention FPA scores. \\
\hline \multirow[t]{6}{*}{ Redmond $^{3}$} & I. Questionnaire I administered pre-intervention & Trends identified: \\
\hline & 2. Questionnaire 2 administered I month post & - A reduction in the rate of tripping \\
\hline & intervention & - Positive parental satisfaction with the treatment \\
\hline & & NNT: \\
\hline & & - Tripping more than once daily $=1.8$ \\
\hline & & - FPA more than 2 SDs from population mean $=3.0$ \\
\hline \multirow[t]{6}{*}{ Munuera $^{20}$} & I. FPA barefoot (unshod) (AGI) & A significant FPA improvement from barefoot \\
\hline & 2. FPA shod (physiologic/standardized shoewear) (AG2) & to shod (AGI-AG2), with an even greater FPA \\
\hline & 3. FPA shod + orthotic device (AG3) & improvement in shod + orthoses condition (AGI-AG3). \\
\hline & & AGI-AG2 $=1.60^{\circ}$ improvement in intoeing \\
\hline & & AG2-AG3 $=3.60^{\circ}$ improvement in intoeing \\
\hline & & AGI-AG3 $=5.30^{\circ}$ improvement in intoeing \\
\hline
\end{tabular}


Table 4 Body of evidence matrix

\begin{tabular}{|c|c|c|}
\hline Component & Grade & Comments \\
\hline Evidence base & $\begin{array}{l}\text { D - Poor } \\
\text { Level IV studies, or level I to III studies with } \\
\text { high risk of bias }\end{array}$ & $\begin{array}{l}\text { - Five studies } \\
\text { - Study design: IV (Level 4) - Case series with either } \\
\text { post-test or pre-test/post-test outcomes }(n=5) \\
\text { - Increased risk of bias due to poor methodological quality } \\
\text { of studies } \\
\text { - Use of outcome measures with demonstrable } \\
\text { psychometric properties } \\
\text { - Only one study calculated sample size estimate }\end{array}$ \\
\hline Consistency & $\begin{array}{l}\text { C - Satisfactory } \\
\text { Some inconsistency reflecting genuine uncertainty } \\
\text { around clinical question }\end{array}$ & $\begin{array}{l}\text { - All five studies level IV studies } \\
\text { - Three of the five studies use the same outcome measure } \\
\text { - Three of the five studies report similar results }\end{array}$ \\
\hline Clinical impact & $\begin{array}{l}\text { D - Poor } \\
\text { Slight or restricted }\end{array}$ & $\begin{array}{l}\text { - Only one study provided long term follow-up } \\
\text { of treatment outcome }(I \text { month post-base line }) \\
\text { - Small patient population }(n=2 \mid 7)\end{array}$ \\
\hline Generalizability & $\begin{array}{l}\text { C - Satisfactory } \\
\text { Population/s studied in the body of evidence differ } \\
\text { to target population but it is clinically sensible } \\
\text { to apply this evidence to target population }\end{array}$ & $\begin{array}{l}\text { - Only five studies of questionable quality } \\
\text { - Age range }<I \text { year- } 6.8 \text { years. One study provided mean } \\
\text { and standard deviation ranges and one study the mean } \\
\text { and SD could be calculated based on available data } \\
\text { - Higher percentage of female participants in the overall } \\
\text { sample included in this review }\end{array}$ \\
\hline Grade of recommendation & $\begin{array}{l}\text { D - Caution } \\
\text { Body of evidence is weak and recommendation } \\
\text { must be applied with caution }\end{array}$ & $\begin{array}{l}\text { - Five, low level (case series), low quality (increased risk } \\
\text { of bias due to poor methodological quality of studies) } \\
\text { evidence base } \\
\text { - While some of the findings were consistent there } \\
\text { were issues with small sample size, lack of use of } \\
\text { psychometrically sound outcome measures, and no long } \\
\text { term follow-up, which are important methodological flaws }\end{array}$ \\
\hline
\end{tabular}

Abbreviation: SD, standard deviation.

\section{Discussion}

Despite intoeing being a commonly seen clinical problem, there is a significant gap on "what works" for this population. Therefore, the aim of this systematic review was to identify and critique the best available evidence for the nonsurgical management of an intoed gait pattern in a pediatric population. The literature searching identified only five case studies to inform this systematic review. ${ }^{3,7,14,20,26}$ Despite the limited body of research evidence, which poses unique challenges for health care professionals who routinely encounter this problem, the findings from this review provide opportunities for reflection. While recognizing its limitations, both in terms of quantity and quality, there is an emerging body of evidence which weakly supports the use of gait plates and orthotic devices with a gait plate extension in the management of a pediatric intoed gait pattern.

Overall, the methodological quality of the included studies was poor. Many studies failed to account for selection bias, measurement bias, confounders, and loss to follow-up. The study by Redmond was an exception among this cohort of studies, controlling for selection and measurement bias but failing to control confounders. ${ }^{3}$ Selection of participants in these research initiatives was poorly reported by the majority of the studies (four out of five). The study by Munuera and colleagues was the exception which clearly defined an inclusion and exclusion criteria. ${ }^{20}$ Whilst Munuera and colleagues did not have a minimum level of intoeing required, they did exclude children with motor alterations or serious deformities of the lower limb that would affect gait, a history of surgical management of the lower limb, or children presenting requiring surgical management.

As previously acknowledged, intoeing is the resultant gait pattern caused by the presence of a number of different underlying pathologies, be they structural or postural. Two studies described the presence of the underlying pathologies within their cohort of children but did not complete any sub-group analysis. ${ }^{714}$ It is a significant design flaw that these sub-group analyses have not been acknowledged and systematically accounted for in the results. An adequate clinical assessment of an intoed gait pattern should include an extensive assessment as to what underlying pathology is driving this resultant gait pattern. Without this accurate diagnosis, a targeted management plan cannot be implemented. 
The absence of these sub-group analyses greatly reduces the application of these results to the clinical population.

Measurement bias was poorly controlled within the five studies reviewed. All of the FPA measurements were collected with a mixture of both barefoot and shod conditions and by using different footprint bisection lines. The results within the studies of both before and after the intervention and between the studies are not wholly comparable with the differing barefoot and shod conditions. As previously stated, Milliron and colleagues demonstrated with their pilot study that a footprint (barefoot) bisection line through the middle of the second toe was the most reliable point for measurement. ${ }^{27}$ This point of bisection was not used consistently within the five studies reviewed. The lack of measurement consistency both within and between the studies once again reduces the relevance of these results to the clinical population.

The only study to utilize an outcome measure other than the FPA was Redmond. ${ }^{3}$ The questionnaires initiated at pre and post intervention demonstrated both parental satisfaction and a reduction in the rate of tripping amongst the intoeing cohort. Investigating parental satisfaction is a significant inclusion as parental concern as to the aesthetics of the child's gait pattern will primarily drive these referrals. ${ }^{3-5,7-11}$ Although the results as a whole have been clouded by the aforementioned measurement biases, the results from the Redmond study show promising trends for the use of gait plates, both for the parent and the child. ${ }^{3}$

\section{Limitations of this review}

The very nature of a systematic review ensures a very specific, targeted body of literature is identified, accessed, evaluated, and synthesized. As the review only included published, English language literature, the potential for publication and language bias should be acknowledged. While the authors made all attempts to identify and access all relevant studies, it is possible, due to differing terminologies, and access to databases and journals, some may have been missed. Finally, this review is based on a small body of evidence (five studies) which were underpinned by several methodological flaws. While the number and quality of primary research is beyond the authors' control, it must be acknowledged when considering the findings from this review.

\section{Conclusion}

\section{Implications for clinical practice}

There is a lack of published high level, methodologically sound evidence for the non-surgical management of a pediatric intoed gait pattern. The body of evidence that does exist is small $(n=5)$ and of varied quality. There is generally weak evidence that suggests that gait plates and orthotic devices with a gait plate extension may assist in the management of a pediatric intoed gait pattern. However, due to concerns with the methodological quality of the evidence base, this recommendation must be applied with caution. Intoeing may be the resultant gait pattern from the presence of one or multiple underlying pathologies. Although the current evidence base is flawed in not considering the assessment and/or sub-group analysis of any of these pathologies, good clinical practice should not exclude a thorough clinical assessment for the diagnosis of one of these underlying pathologies.

Due to this limited and weak evidence base, clinical practice continues to be guided by clinician's expertize and experiential knowledge. It is imperative that interpretation and implementation of these findings in clinical practice is underpinned by clinical reasoning and regular monitoring of patient outcomes.

\section{Implications for future research}

Future research needs to specifically address the underlying pathologies driving the intoed gait pattern, for without this consideration the results are neither specific nor applicable to current clinical practice. Future research should endeavor to use well described samples with adequate sample size, robust methodological design to control for bias, and outcome measures with strong psychometric properties with data collected over a long period of time.

\section{Disclosure}

The authors report no conflicts of interest in this work.

\section{References}

1. Molony D, Hefferman G, Dodds M, McCormack D. Normal variants in the paediatric orthopaedic population. Ir Med J. 2006;99(1):13-14.

2. Briggs RG, Carlson WO. The management of intoeing: a review. $S D$ J Med. 1990;43(2):13-16.

3. Redmond AC. The effectiveness of gait plates in controlling in-toeing symptoms in young children. $J$ Am Podiatr Med Assoc. 2000;90(2):70-76.

4. Ryan DJ. Intoeing. A developmental norm. Orthop Nurs. 2001; 20(2):13-18.

5. Malone M. Rotational deformities of the lower limb in children - a primary cause of intoeing. Podiatry Now. 2007;10(10):29-36.

6. Killam PE. Orthopedic assessment of young children: developmental variations. Nurse Pract. 1989;14(7):27-36.

7. Redmond AC. An evaluation of the use of gait plate inlays in the short-term management of the intoeing child. Foot Ankle Int. 1998;19(3):144-148.

8. Li YH, Leong JC. Intoeing gait in children. Hong Kong Med J. 1999;5(4):360-366.

9. Williams PF. Intoeing in Children. Med J Aust. 1960;47(2):16-19.

10. Sharrard WJ. Intoeing and flat feet. Br Med J. 1976;1(6014): 888-889. 
11. Gulan G, Matovinović D, Nemec B, Rubinić D, Ravlić-Gulan J. Femoral neck anteversion: values, development, measurement, common problems. Coll Antropol. 2000;24(2):521-527.

12. Svenningson S, Terjesen T, Apalset K, Anda S. Osteotomy for femoral anteversion: A prospective 9-year study of 52 children. Acta Orthop Scand. 1990;61(4):360-363.

13. Payne LZ, DeLuca PA. Intertrochanteric versus supracondylar osteotomy for severe femoral anteversion. J Pediatr Orthop. 1994;14(1):39-44.

14. Knittle G, Staheli LT. The effectiveness of shoe modifications for intoeing. Orthop Clin North Am. 1976;7(4):1019-1025.

15. Staheli LT. Intoeing in Children. Prim Care. 1978;5(1):97-110.

16. Staheli LT. Lower positional deformity in infants and children: a review. J Pediatr Orthop. 1990;10(4):559-563.

17. Lösel S, Burgess-Milliron J, Micheli LJ, Edington CJ. A simplified technique for determining foot progression angle in children 4 to 16 years of age. J Pediatr Orthop. 1996;16(5):570-574.

18. Matovinović D, Nemec B, Gulan G, Šestan B, Ravlić-Gulan J. Comparison in regression of femoral neck anteversion in children with normal, intoeing and outtoeing gait - prospective study. Coll Antropol. 1998;22(2):525-532.

19. Svenningson S, Apalset K, Terjesen T, Anda S. Regression of femoral anteversion: A prospective study of intoeing children. Acta Orthop Scand. 1989;60(2):170-173.

20. Munuera PV, Castillo JM, Dominguez G, Lafuente G. Orthotic devices with out-toeing wedge as treatment for in-toes gait in children. $J \mathrm{Am}$ Podiatr Med Assoc. 2010;100(6):472-478.

21. Fabry G, Cheng LX, Molenaers G. Normal and abnormal torsional development in children. Clin Orthop Relat Res. 1994;(302):22-26.

22. Karol LA. Rotational deformities in the lower extremities. Curr Opin Pediatr. 1997;9(1):77-80.

23. Rosman MA. Intoeing. Easing parents' concerns. Patient Care. 1987;21(12):173-179.

24. Stricker SJ, Sama AA. Assessment of angulation and torsion of lower limbs in children. Int Pediatr. 2001;16(3):138-143.
25. Scherl SA. Common lower extremity problems in children. Pediatr Rev. 2004;25(2):52-61.

26. Lanier JC. The intoeing child. Treament with a simple orthopedic appliance. J Fla Med Assoc. 1971;58(12):19-23.

27. Milliron M, Loesel S, Micheli L, Edington C. Comparison of methods for calculation of foot progression angle. J Am Coll Sports Med. 1992;24(5):S173.

28. Yngve DA. Foot-progression angle in clubfeet. J Pediatr Orthop. 1990;10(4):467-472.

29. Staheli LT. Report of the Pediatric Orthopaedic Society (POS) Subcommittee on Torsional Deformity. Orthop Trans. 1980;4:64-65.

30. Staheli LT, Corbett M, Wyss C, King H. Lower-extremity rotational problems in children. Normal values to guide management. $J$ Bone Joint Surg Am. 1985;67(1):39-47.

31. Sass P, Hassan G. Lower extremity abnormalities in children. Am Fam Physician. 2003;68(3):461-468.

32. Evans AM. The flat-footed child - to treat or not to treat: what is the clinician to do? J Am Podiatr Med Assoc. 2008;98(5):386-393.

33. National Health and Medical Research Council (NHMRC). A guide to the development, implementation and evaluation of clinical practice guidelines. 1998. Australia. Available from: http://www.nhmrc. gov.au/_files_nhmrc/file/publications/synopses/cp30.pdf. Accessed December 19, 2011.

34. The Critical Appraisal Skills Programme. Cohort Studies Critical Appraisal Tool. 2004. Oxford. Available from: http://www.phru. nhs.uk/Doc_Links/cohort\%2012\%20questions.pdf. Accessed December 19, 2011.

35. NHMRC levels of evidence and grades for recommendations for developers of guidelines. 2009. Australia. Available from: http://www. nhmrc.gov.au/_files_nhmrc/file/guidelines/evidence_statement_form pdf. Accessed December 19, 2011.
Journal of Multidisciplinary Healthcare

\section{Publish your work in this journal}

The Journal of Multidisciplinary Healthcare is an international, peerreviewed open-access journal that aims to represent and publish research in healthcare areas delivered by practitioners of different disciplines. This includes studies and reviews conducted by multidisciplinary teams as well as research which evaluates the results or conduct of such teams or

\section{Dovepress}

healthcare processes in general. The journal covers a wide range of areas and welcomes submission from practitioners at all levels, from all over the world. The manuscript management system is completely online and includes a very quick and fair peer-review system. Visit http://www.dovepress.com/testimonials.php to read real quotes from published authors. 